\title{
Estudio longitudinal de la capacidad de representación simbólica de niños y niñas en el ciclo 3-6 de Educación Infantil al abordar tareas relativas a dictados matemáticos
}

\author{
Longitudinal study of the symbolic representation capacity in children in \\ the 3-6 cycle of Early Childhood Education in tasks related to mathematical \\ dictation
}

\author{
María Luisa Novo* \\ ORCID iD 0000-0001-6621-1255 \\ Ainhoa Berciano** \\ ORCID iD 0000-0001-7399-4745
}

\begin{abstract}
Resumen
En este trabajo se utilizan los dictados matemáticos, como enfoque didáctico-instrumental, para realizar un estudio longitudinal sobre la capacidad de representación matemática de niños y niñas en edades tempranas, caracterizando sus producciones. Para tal fin, se ha realizado un estudio de campo con una muestra total de 104 niñas y niños de $1^{\circ}, 2^{\circ}$ y $3^{\circ}$ de Educación Infantil. Los resultados obtenidos, independientemente de la edad, son: a) se evidencia una relación positiva entre el índice de dificultad de los dictados y el porcentaje de niños y niñas que no completan su tarea con éxito; b) la repetición de tareas, dentro del mismo dictado, con difícultad equivalente fomenta el aprendizaje significativo, independientemente del nivel cognitivo de las niñas y de los niños; c) en consonancia con los niveles de Van Hiele, se detectan mayores dificultades en la representación simbólica de objetos con mayor grado de abstracción y complejidad matemática.
\end{abstract}

Palabras clave: Representaciones simbólicas. Dictados matemáticos. Educación infantil. Estudio longitudinal. Niveles de Van Hiele.

\begin{abstract}
In this work, mathematical dictations are used as a didactical-instrumental approach to perform a longitudinal study on the mathematical representation capacity in children at an early age. For this purpose, a field study was carried out with a total sample of 104 girls and boys of 1 st, $2^{\text {nd }}$, and 3rd grade of Early Childhood Education. The results obtained, regardless of the age group, are: a) there is a positive relationship between the difficulty index of the dictates and the percentage of children who did not complete their task successfully; b) the repetition of tasks, within the same dictation, with equivalent difficulty fosters significant learning, regardless of the cognitive

\footnotetext{
* Doctora en Didáctica de las Matemáticas por la Universidad de Valladolid (UVA). Profesora en la Facultad de Educación y Trabajo Social (FeyTS) de la Universidad de Valladolid (UVA), Valladolid, España. Dirección postal: Paseo de Belén, 1, 47011, Valladolid, España. E-mail: marialuisa.novo@uva.es.

** Doctora en Matemáticas por la Universidad de Sevilla (US). Profesora en la Facultad de Educación de Bilbao de la Universidad del País Vasco/Euskal Herriko Unibertsitatea (UPV/EHU), Bizkaia, España. Dirección postal: Barrio Sarriena, s/n, 48940, Leioa (Bizkaia), España. E-mail: ainhoa.berciano@ehu.eus.
} 
level, for girls and boys; c) according to the Van Hiele levels, greater difficulties are detected in the symbolic representation of objects when a higher degree of abstraction and mathematical complexity appear.

Keywords: Symbolic representations. Mathematical dictations. Childhood Education. Longitudinal study. Van Hiele Levels.

\section{Introducción}

Según Devlin (2002), el siglo XXI está invadido por todo tipo de medios de comunicación y por informaciones diversas, en las que las matemáticas tienen, todavía, que abrir muchas puertas. Casi todos los aspectos de nuestra vida, de alguna manera, están relacionados con ellas, ya que sus distintos niveles de abstracción son la esencia primaria del pensamiento, de la comunicación, del cálculo, de la sociedad y de la vida.

Este interés por la abstracción matemática y sus implicaciones en la vida cotidiana ha dado lugar a numerosas investigaciones, con el fin de responder a distintos aspectos de la misma; desde cómo se define hasta cómo trabajarla en el aula de matemáticas. En este sentido, cada vez hay más estudios que muestran la necesidad de una educación matemática de calidad en edades tempranas, debido a que favorece la adquisición de habilidades matemáticas (OCDE, 2011) y, a pesar de ello, todavía prevalece la creencia entre personas ajenas a las tareas educativas de que los primeros aprendizajes relacionados con las matemáticas se dan a los 6 años (EDO, 2012); e incluso en algunos docentes predomina la idea de que en Educación Infantil no es factible desempeñar trabajos matemáticos de calidad (CHAMORRO, 2008). Aun así, cada vez son más las investigaciones que, haciendo uso de enfoques metodológicos distintos, muestran cómo la enseñanza-aprendizaje de las matemáticas en infantil abre a los niños y a las niñas la mirada hacia un mundo nuevo (CANALS, 2001; ALSINA et al., 2007; PLANAS; ALSINA, 2009; entre otros).

Otra corriente de investigación importante se centra en el análisis del grado de aplicabilidad y repercusión que tienen algunos recursos didácticos en el aula de Educación Infantil. Así, en este caso, centramos nuestra atención en el dictado matemático como instrumento didáctico. A pesar de la ausencia de muchos trabajos de investigación, encontramos que los dictados matemáticos ya han sido utilizados por Berciano, Novo y Alsina (2017), donde se han investigado las potencialidades de éstos como herramienta didáctica para el desarrollo del pensamiento lógico-matemático y su aplicación al aula de cuatro años, concluyendo que, en esta edad, los dictados favorecen la representación simbólica y que dichas tareas, bien planificadas, suponen una buena práctica docente.

En el presente artículo se concibe la necesidad de profundizar en el estudio de la 
repercusión del uso de dictados matemáticos en el aula de Educación Infantil, focalizando nuestro interés en la caracterización de la capacidad de representación simbólica de niños y niñas de 3 a 6 años, en la que se analice profusamente cuál es la evolución del tipo de representación que niños y niñas pueden hacer, dependiendo de sus edades; abriendo, así, un nuevo campo de estudio que analice las posibles relaciones entre la competencia matemática y la comunicativa, fusionando comunicación oral y gráfica.

En este sentido, con el fin de abordar con éxito nuestro objetivo de investigación, éste ha sido subdividido en tres objetivos secundarios: 1) precisar el porcentaje de niños y niñas que no completan su tarea con éxito y la posible relación que tiene con la dificultad del dictado; 2) valorar en qué medida el dictado favorece la asimilación de conceptos matemáticos abstractos equivalentes; $\mathrm{y}, 3)$ detectar qué objetos matemáticos resultan de mayor complejidad en el diseño, implementación y representación de los dictados.

\section{Marco teórico}

Siguiendo a la OCDE (2011), el PISA muestra que una enseñanza-aprendizaje desde edades tempranas beneficia nuestra capacidad matemática $\mathrm{y}$, por consiguiente, esboza el planteamiento de conseguir reformar los currículos para que desde las primeras edades se realicen actividades matemáticas eficaces para el desarrollo de su pensamiento lógicomatemático.

Por tanto, uno de los objetivos de la investigación en Didáctica de la Matemática, en esta etapa educativa, es dar respuesta a la manera de emprender la enseñanza-aprendizaje de la matemática en el aula de Educación Infantil, entendida ésta como "la matemática escrita y simbólica que se imparte en las escuelas y que supera las limitaciones de la matemática informal" (BAROODY, 1994, p. 45).

En este sentido, son varias las investigaciones que abordan el desarrollo y evolución del pensamiento matemático, pero todas ellas revelan un progreso a largo plazo de la percepción y la acción físicas, a través del desarrollo del simbolismo y del lenguaje, encaminadas hacia el razonamiento deductivo. Por ejemplo, Piaget e Inhelder (1969) enuncian el desarrollo de las niñas y los niños a través de distintas etapas, donde la que corresponde al ciclo 3-6 es la pre-operativa en la que se perfeccionan el lenguaje y las imágenes mentales desde una perspectiva personal.

Para Bruner (1966) este desarrollo se expresa a través de tres formas de representación: la enactiva (fundamentada en la acción), la icónica (sustentada por imágenes) 
y la simbólica (incluye símbolos tanto lingüísticos como matemáticos). Fischbein (1987) concibe tres enfoques en el desarrollo de las matemáticas: intuitivo, algorítmico y formal; donde la intuición está claramente relacionada con la representación enactiva e icónica de Bruner. Cada uno de estos marcos muestra un progreso hacia el razonamiento deductivo, partiendo de la percepción y la acción concretas y avanzando con el simbolismo y el lenguaje.

Por otro lado, Tall $(2009,2013)$ afirma que las fases del desarrollo cognitivo de los niños y las niñas son: la percepción, la acción y la reflexión, siendo las dos primeras fases, las correspondientes a los denominados mundo corpóreo (a través de las propiedades de los objetos se construyen imágenes mentales) y mundo simbólico (las acciones entre objetos dan lugar a procedimientos matemáticos), las que deben trabajarse en la etapa infantil para poder sentar las bases hacia el mundo formal.

A pesar de las diferencias y distintos matices existentes entre los enfoques anteriores, debemos destacar que, de modo implícito, todos insisten en la necesidad de establecer relaciones entre diversos sistemas de representación; donde las distintas representaciones en Educación Infantil deben ser la base para ordenar, reconocer y manifestar ideas matemáticas, ser utilizadas para interpretar situaciones de la vida cotidiana y favorecer el aprendizaje haciendo uso de las representaciones adecuadas a cada situación, con el fin de resultar significativas.

En esta misma línea, Berdonneau (2008) enfatiza la necesidad de trabajar la representación mental en edades tempranas; estableciendo conexiones entre las diversas informaciones (sobre todo, las percepciones sensoriales) que los niños y las niñas recogen durante sus intentos anteriores, dando lugar a la creación y elaboración de conceptos. Por tanto, la actividad que se realice en el aula sólo tendrá éxito si se da una representación mental en la que un apoyo lingüístico es fundamental.

Los niños y las niñas se encuentran con un primer desafío para llegar a esclarecer el significado existente más allá de una representación externa, esto es, comprender la naturaleza compleja del objeto y pasar de su carácter manipulativo y convencional para concentrarse en el significado simbólico, dando lugar a iniciar los primeros pasos de la interpretación (PÉREZ-ECHEVARRÍA; MARTÍ; POZO, 2010).

Dentro de las representaciones externas, según Martí y Pozo (2000), predominan dos tipos: las que no son estáticas (el lenguaje oral) y las que son duraderas como la escritura y la notación matemática, pero, en ambos casos, se precisan operaciones mentales de entendimiento y elaboración que son efectuadas por métodos de resolución interna, donde, es claro que a los niños y las niñas les resulta más complicado realizar las producciones que 
entender lo que están viendo y la capacidad de representar implica la necesidad de diferenciar, examinar y caracterizar los distintos objetos.

En este sentido, Llach y Alsina (2012, p.331-332 apud Vygotsky, 1978) analizan cómo se relaciona la notación lingüística y la matemática, concluyendo que "para introducir la enseñanza de los sistemas de notación, es necesario partir de las posibilidades cognoscitivas de los niños y considerar su zona de desarrollo próximo".

Así, cuando restringimos nuestro interés de estudio a tareas relacionadas con representación geométrica, Van Hiele (1986) postula distintos niveles en el desarrollo de la comprensión geométrica en los estadios iniciales del aprendizaje de la geometría. Los niños y niñas de Educación Infantil pueden alcanzar como máximo un nivel 0 o 1 de comprensión, en el que las figuras son juzgadas, mayoritariamente, por su apariencia.

Con el fin de salvar las dificultades que implica la reproducción simbólica, en sus investigaciones se utilizaron materiales didácticos como el geoplano para construir las figuras (VAN HIELE, 1959). Es más, en Van Hiele (1999) se indica que, en los niveles de geometría, el más bajo es el nivel visual, que comienza con el pensamiento no verbal. A nivel visual, los niños y las niñas pueden reconocer un rectángulo porque se parece a una caja, mientras que en el siguiente nivel es imprescindible el lenguaje para describir las formas.

Por otra parte, con el fin de ahondar en la comprensión del cuadrado en la escuela infantil, Halat y Yesil-Dagli (2016) llevan a cabo un estudio en el que piden a niños y niñas de 5-6 años que identifiquen cuadrados de una lista de figuras planas dibujadas en un papel, organizadas según los niveles de Van Hiele, concluyendo que el porcentaje de errores cometidos en la identificación de cuadrados es del $79 \%$ cuando estos no aparecen dibujados con dos de sus lados paralelos al eje vertical del papel, y del $56 \%$ cuando estos tienen dos lados perpendiculares al eje vertical del papel. Además, un $35 \%$ de los niños y niñas no son capaces de dibujar un cuadrado de forma precisa.

Igualmente, Yesil-Dagli y Halat (2016, p.189) realizan un estudio exploratorio de la comprensión conceptual del triángulo en niños y niñas de 5-6 años e indican que:

[...] El área más difícil fue identificar los tipos de triángulos, donde se presentaban un triángulo isósceles y un triángulo rectángulo, seguidos por identificaciones de triángulos en diferentes orientaciones, específicamente volteadas y giradas. Los niños parecían identificar y clasificar el triángulo basándose en el prototipo visual. Estos hallazgos proporcionan soporte para la teoría de prototipos, la teoría de van Hiele y para los trabajos de Clements y sus colegas.

Posteriormente, con el fin de analizar qué son capaces de hacer niños y niñas de 4-5 años en tareas de representación simbólica, en Berciano, Novo y Alsina (2017) se presenta una investigación en la que la herramienta didáctica usada para tal fin es el dictado 
matemático, concluyendo que, en esta edad, el error más habitual viene determinado por la falta de distinción de formas geometricas y tamaños relativos.

Así, teniendo en cuenta la trascendencia del trabajo de la representación con los más pequeños, en este artículo nos centramos en la caracterización de la capacidad de representación simbólica de niños y niñas de 3 a 6 años, a través del nexo de unión que los dictados matemáticos dan entre la representación oral y simbólica ( NOVO; BERCIANO; FERNÁNDEZ, 2017), asumiendo los mismos como herramienta didáctica que vincula el lenguaje oral y el pensamiento lógico matemático con el enfoque dirigido al desarrollo del pensamiento simbólico.

El dictado, en su formato más clásico, es una de las prácticas que se suele emplear en el aula para pasar del lenguaje oral al lenguaje escrito. Partiendo de una entrada de enunciado verbal, se transforma en lengua escrita, conllevando un método de resolución interna o proceso mental (FRACA DE BARRERA, 2007). Todo ello convierte al dictado, no sólo en una herramienta didáctica válida para trabajar la ortografía, sino en un recurso didáctico ventajoso en el aula.

Para que un dictado sea efectivo, Moya y García (1998) reconocen dos requisitos que deben satisfacerse: por un lado, es imprescindible la cooperación entre dos personas (emisora y receptora) y, por otro, el enunciado difundido ha de estar debidamente fragmentado para que la persona receptora pueda recordar la información y reconstruir el contenido global.

Existen muchas clases de dictados y, aunque varían las propuestas y objetivos, siempre se encuentran aspectos comunes a todos ellos. Por ejemplo, en la práctica de dictados musicales Arriaga y Madariaga (2004) destacan que, antes de efectuar el dictado, es necesario comprobar que los niños y las niñas conozcan las notas que van a ser utilizadas y, como en casi todos los dictados, incluidos los lingüísticos o matemáticos, la tarea se debe presentar perfectamente dividida en secciones, repitiendo cuando sea oportuno y revisando las respuestas.

Así, al realizar dichas tareas se mejora la concentración y se desarrollan la atención a través de la audición, el entendimiento y la representación; además, concurren diferentes elementos al mismo tiempo, en el que no sólo se trata de comprender lo que se escucha, sino que es imprescindible lograr la representación de lo que se ha oído y, por lo tanto, hay que rescatar los conocimientos previos y profundizar sobre los mismos de manera inminente.

Según Viera (2009), es importante elegir los momentos adecuados para que los niños y las niñas sean capaces de realizar las representaciones de las diversas consignas sobre el papel $\mathrm{y}$, para ello, se necesita: i) precisión tanto en la percepción visual como en la auditiva; ii) 
atención, concentración y memoria.

Volviendo al caso que nos concierne, en consonancia con Berciano, Novo y Alsina (2017), en los dictados matemáticos los niños y las niñas deberán representar diversas figuras que verifiquen ciertas peculiaridades en una progresión creciente de dificultad. Esta dificultad debe venir marcada por una trayectoria de aprendizaje (CLEMENTS; SARAMA, 2015), donde los niños y niñas participen en distintas tareas según el nivel de pensamiento en el que se encuentren para obtener los objetivos marcados.

En este sentido, Novo, Berciano y Fernández (2017) muestran el diseño de una actividad de aula en la que los dictados son usados con el fin de crear un nexo entre la representación oral y simbólica. Además, siempre y cuando la secuencia diseñada sea correcta, los niños y las niñas pueden completar la tarea con éxito, por lo que los dictados matemáticos son una herramienta didáctica válida para fomentar la simbolización matemática y garantizar los objetivos que se persiguen (BERCIANO; NOVO; ALSINA, 2017).Y, además, al recoger consignas orales sobre papel, el alumnado se va encaminando de forma adecuada para las prácticas de dictados tradicionales en Primaria (NOVO, 2015).

\section{Metodología}

Nuestro estudio se enmarca en un paradigma interpretativo. Desde este enfoque y, de acuerdo con los objetivos descritos en la introducción, se ha llevado a cabo un estudio de campo con un análisis inicialmente cualitativo y, posteriormente, cuantitativo, esto es, se ha abordado desde la perspectiva de un diseño de investigación mixto. Hemos optado por dicho método pues según señala Cameron (2010) las investigaciones con este tipo de diseños representan el más alto grado de integración o combinación entre los enfoques cualitativo y cuantitativo.

En Díaz López (2014) se expone que los diseños de investigación mixtos, también conocidos como Mixed Methods Research (MMR), surgen porque en algunas ocasiones los dos paradigmas tradicionales de investigación no resuelven todos los problemas y se trata de abrir nuevos caminos utilizando las bondades de ambos paradigmas para conseguir mejores resultados, sobre todo, en temas educativos.

Este método personifica un procedimiento ordenado, experimental y crítico de la investigación. Por un lado se valora el enfoque subjetivo de la investigación cualitativa y se completa con el análisis objetivo de la investigación cuantitativa. Aún así, numerosas investigaciones analizan la fiabilidad de los MMR, en la que uno de los problemas que se 
identifican frecuentemente son las estrategias para analizar de forma integrada los datos (BRYMAN, 2006 ; GREENE; CARACELLI; GRAHAM ,1989).

En este sentido, Moscoso (2017) afirma que los MMR suponen un camino válido de investigación si cumplen las siguientes pautas: buena formalización, reflexión en su desarrollo e importancia del contexto de trabajo.

Con base a estos planteamientos, nuestro estudio se clasifica dentro de una metodología de investigación basada en un MMR debido a que, por una parte, pretende evidenciar y comprender los fenómenos vinculados a las tareas de representación simbólica de niños y niñas de distintas edades $y$, por otra, facilitar el fortalecimiento de los conocimientos teóricos y prácticos. Dicha metodología supone una recopilación, exploración e interpretación de hechos cualitativos y cuantitativos que hemos escogido por ser imprescindibles para realizar nuestro trabajo.

\subsection{Contexto del estudio de campo}

La experimentación se ha realizado en el Colegio de Educación Infantil y Primaria CEIP Federico García Lorca de Valladolid. La muestra ha estado compuesta por 104 niños y niñas de $1^{\circ}, 2^{\circ}$ y $3^{\circ}$ de Educación Infantil con edades comprendidas entre los 3 y los 6 años de edad distribuidos conforme a la Tabla 1:

Tabla 1 - Distribución de participantes según edad, curso y sexo

\begin{tabular}{cccc}
\hline Curso & Niñas & Niños & Total \\
\hline Primero & 6 & 9 & 15 \\
Segundo & 21 & 26 & 47 \\
Tercero & 21 & 21 & 42 \\
\hline Total & 48 & 56 & 104 \\
\hline \multicolumn{2}{r}{ Fuente: Elaborada por las autoras }
\end{tabular}

\subsection{Diseño, procedimiento y estructura de la implementación}

Tal como se describe en Berciano, Novo y Fernández (2017), la actividad requiere de un contexto docente y de gestión. En concreto, previamente a la experimentación, se realizan juegos en gran grupo, utilizando figuras geométricas de cartón, con características de color, forma y tamaño diferentes con el fin de determinar los conceptos previos de los niños y las niñas (análogo a lo sugerido para los dictados musicales por ARRIAGA; MADARIAGA, 2004). Posteriormente, en las mesas se encuentran la plantilla y los rotuladores que van a precisar cada niña o niño. La maestra enuncia despacio el contenido de cada sección del dictado mientras que los niños y las niñas realizan las diferentes representaciones simbólicas, 
siguiendo las indicaciones dadas (ver secuenciación en la figura 1).

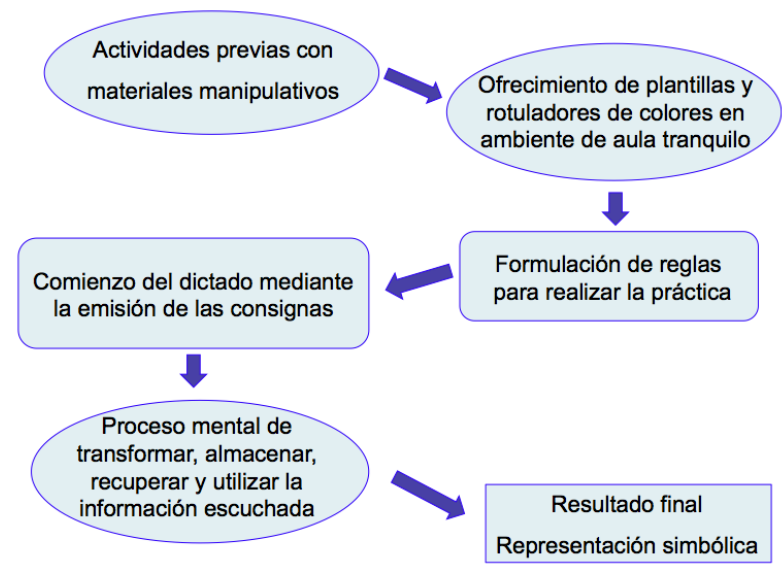

Figura 1 - Secuenciación de la actividad en el aula

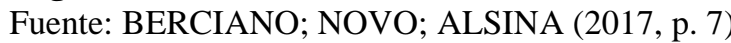

La tarea se ha puesto en marcha en uno de los rincones de trabajo, fomentando la concentración en la realización de la actividad (VIERA, 2009), de forma que los escolares vayan pasando en grupos de cinco, realicen la actividad en una mesa y continúen en otro rincón diferente. Con respecto a la organización temporal, ésta se ha llevado a cabo en dos fases; la primera se ha producido en los últimos días del primer trimestre y la segunda a finales del último trimestre en todas las aulas de infantil del centro.

\subsection{Diseño teórico de los dictados dependiendo de la edad}

Los dictados han sido diseñados para resultar compatibles con el desarrollo cognitivo medio del alumnado de infantil según su edad, atendiendo a los estándares de contenido del National Council of Teachers of Mathematics (NCTM, 2003) y a las trayectorias hipotéticas de aprendizaje de (CLEMENTS; SARAMA, 2015). Este hecho ha dado lugar a que los dictados tuvieran un nivel de dificultad multinivel, dependiendo del niño o niña que fuera a realizarlo, pero, en todo caso, se ha planteado como una actividad accesible a todo el alumnado correspondiente.

En concreto, teniendo en cuenta los estándares de contenido que deben tratarse en la etapa de educación infantil (NCTM, 2003), las características de los dictados usados pueden verse en el Cuadro 1: 


\begin{tabular}{|c|c|c|c|c|}
\hline $\begin{array}{l}\text { Estándares de } \\
\text { contenidos }\end{array}$ & $\begin{array}{c}\text { Sub- } \\
\text { contenidos }\end{array}$ & Edad 3 años & Edad 4 años & Edad 5 años \\
\hline $\begin{array}{l}\text { Números y } \\
\text { operaciones }\end{array}$ & Cantidades & $\begin{array}{c}\text { Cuantificadores y } 1,2 \\
\text { y } 3 \text {. }\end{array}$ & $1,2,3$ y 4 & $1,2,3,4,5,6$ \\
\hline Algebra & Cualidades & $\begin{array}{l}\text { Colores: rojo, } \\
\text { amarillo y azul }\end{array}$ & $\begin{array}{l}\text { Colores: rojo, } \\
\text { amarillo y azul }\end{array}$ & $\begin{array}{l}\text { Colores: rojo, } \\
\text { amarillo y azul }\end{array}$ \\
\hline \multirow[t]{2}{*}{ Geometría } & Formas & $\begin{array}{l}\text { Círculo, cuadrado y } \\
\text { triángulo. }\end{array}$ & $\begin{array}{l}\text { Círculo, cuadrado, } \\
\text { triángulo. Sol con } \\
\text { rayos ( relación de } \\
\text { concepto con vida } \\
\text { cotidiana } \\
\end{array}$ & $\begin{array}{l}\text { Círculo, } \\
\text { cuadrado, } \\
\text { triángulo. Sol } \\
\text { con rayos y } \\
\text { flor con pétalos } \\
\end{array}$ \\
\hline & Orientación & No se contempla & $\begin{array}{c}\text { Arriba, abajo y en el } \\
\text { centro }\end{array}$ & $\begin{array}{c}\text { Arriba, abajo, } \\
\text { dentro y "en la } \\
\text { punta" }\end{array}$ \\
\hline Medida & Medidas & No se trata & Grande y pequeño & No se trata \\
\hline
\end{tabular}

Igualmente, los dictados se han diseñado teniendo en cuenta un incremento en la dificultad determinada, no sólo por los contenidos, sino por el número de secciones a completar en cada dictado (llamadas casillas). Así, el dictado para tres años consta de tres casillas, para cuatro años tiene cuatro casillas y cinco casillas para cinco años. A modo de ejemplo, en la Figura 2 se puede ver la estructura de un dictado para niñas y niños de 3 años.

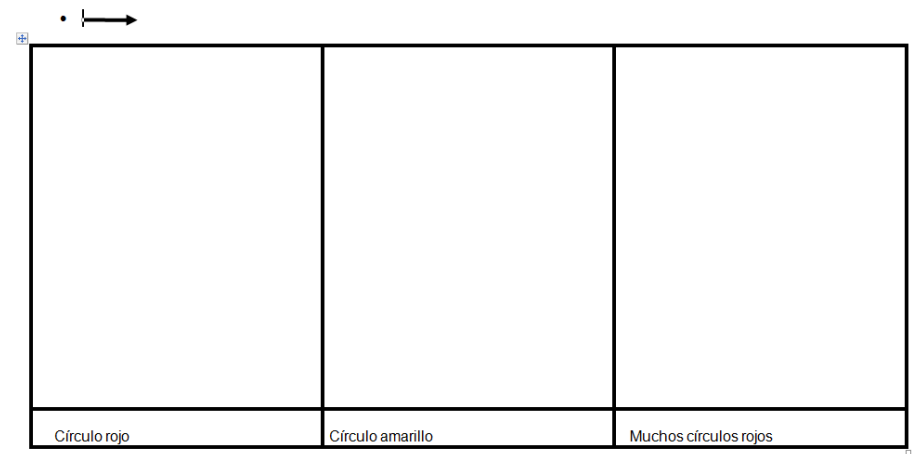

Figura 2 - Plantilla de dictado matemático para tres años en el primer trimestre Fuente: NOVO; BERCIANO; FERNÁNDEZ, (2017, p. 59)

\subsection{Herramientas de análisis}

Para proceder con éxito a la integración y análisis conjunto de los datos recogidos, se han utilizado tres herramientas de análisis distintas, dependiendo del estudio correspondiente. Así, para el análisis cualitativo se ha usado una rúbrica (más abajo detallada), mientras que para el análisis cuantitativo se han usado una matriz, que determina el grado y tipo de error cometido por cada niño o niña, y un índice de dificultad asociado al apartado del dictado correspondiente. 


\subsubsection{Diseño y validación de la herramienta usada para el análisis cualitativo}

Para el estudio cualitativo de los dictados, se ha diseñado y aplicado una rúbrica coherente con los siguientes aspectos: i) motricidad, ii) organización espacial y iii) reconocimiento de figuras matemáticas. Ésta mide el grado de corrección de la representación en los dictados coherente con la edad.

El proceso de diseño y validación de la rúbrica ha constado de dos fases: en la primera, se ha procedido a realizar un diseño teórico, basado en investigaciones previas acerca de las dificultades e hitos que niños y niñas alcanzan en la realización de dibujos, dependiendo de su edad; y, en una segunda fase, se ha usado dicha herramienta como instrumento piloto para el estudio y clasificación de las producciones para, posteriormente, tras un análisis individual de los resultados por parte de todo el equipo de investigación (formado por las maestras del centro y las investigadoras), se ha realizado una triangulación por pares, dando lugar al diseño final de la rúbrica que se muestra en la Tabla 2.

Tabla 2 - Rúbrica usada para el análisis cualitativo

\begin{tabular}{cccc}
\hline Aspectos & & Graduación & \\
\hline Trazo & Muy impreciso & Impreciso & Preciso \\
$\begin{array}{c}\text { Organización del } \\
\text { espacio }\end{array}$ & Muy poco & Poco & Todo \\
$\begin{array}{c}\text { Forma de las } \\
\text { figuras }\end{array}$ & $\begin{array}{c}\text { Bastante } \\
\text { imperfecta }\end{array}$ & Imperfecta & Perfecta \\
\hline & Fuente: Elaborada por las autoras &
\end{tabular}

A continuación, describimos las características teóricas de cada una de las variables evaluadas:

- Motricidad: según Berruezo (2000), dentro de la expresión psicomotricidad es necesario considerar los aspectos cognitivos, afectivos, simbólicos y sensorio-motrices de cada persona para desarrollarse dentro de un contexto social. Entendemos que la psicomotricidad, así considerada, ejerce una labor esencial en el desarrollo integral de la personalidad. En particular nos interesa la motricidad fina, asociada a la mano. A este respecto, Ardanak (2009) afirma que antes de tres años a los niños y a las niñas les encanta dibujar, garabatear y pintar rayas. A los tres años son capaces de completar algunos dibujos, no solamente se garabatea. A los cuatro años se perfecciona el trazo y a los cinco años el trazo es más libre, ya que existen esquemas motores precisos, debido principalmente al incremento de tono muscular.

- Organización del espacio: según Boule (2005) las tareas que encaminan a los niños y a las niñas a ordenar el espacio están relacionadas, esencialmente, con la orientación, ya 
sea de cada niño y niña con su entorno, con otras personas, con los objetos o con la orientación de los objetos entre sí. En este sentido, es importante analizar cómo se colocan las imágenes en los dictados, entendidos estos como medio para trabajar en el microespacio, esto es, el espacio próximo.

- Reconocimiento de formas geométricas: los holandeses Van Hiele ya postularon que en este nivel educativo del aprendizaje de la geometría los niños y las niñas se encuentran en el nivel de visualización, describen los objetos de forma sencilla y tienden a compararlos con elementos familiares (VAN HIELE, 1986). Igualmente, Holloway (1982) plantea la existencia de tres etapas en las que los niños y las niñas tienen la suficiente destreza para reconocer y representar solamente aquellas figuras que logran reconstruir partiendo de sus propias acciones, pero que para llegar a la abstracción, es imprescindible que establezcan relaciones entre los objetos y sus representaciones. En Halat y Yesil-Dagli (2016) se realiza un estudio sobre la comprensión de las formas geométricas en los niños y las niñas de Infantil para el caso del cuadrado, concluyendo que el cambio de ubicación o posición del objeto implica una mayor dificultad de identificación por parte de los niños y las niñas. En YesilDagli y Halat (2016) se plasma una experiencia parecida en cinco y seis años sobre la capacidad de dibujar de memoria un triángulo donde la mayoría del alumnado es capaz de dibujarlo, pero aproximadamente la mitad de las niñas y los niños encontraron problemas para identificar triángulos de diversos tamaños, tipos y orientaciones.

En relación con los trabajos teóricos analizados, se espera que para tres años los tres aspectos evaluados satisfagan un nivel bajo de graduación; para el caso de cuatro años, medio, y para cinco años alto.

\subsubsection{Diseño y validación de la herramienta usada para el análisis cuantitativo}

Se presentan, a continuación, las dos herramientas utilizadas en el análisis cuantitativo de los datos extraídos del estudio de campo.

Para analizar el tipo de producción que realizan los niños y las niñas en estas tareas y poder caracterizarlos, hemos concebido una primera herramienta de análisis semejante a la utilizada por Berciano, Novo y Alsina (2017), que tiene en cuenta los errores que aparecen en cada bloque de contenido matemático que interviene en los dictados (cualidades, números y operaciones, formas geométricas, medidas y orientación). En concreto, para cada niño o niña 
se considera una matriz compuesta por 1s y 0s que determine los errores encontrados en cada parte del dictado (Figura 3).

$$
\mathrm{m}=\left(\begin{array}{ccc}
\mathrm{m}_{11} & \cdots & \mathrm{m}_{15} \\
\vdots & \ddots & \vdots \\
\mathrm{m}_{51} & \cdots & \mathrm{m}_{55}
\end{array}\right)
$$

Figura 3 - Primera herramienta de análisis

Fuente: Elaborada por las autoras

Así, cada matriz consta de un máximo de 25 parámetros ( 5 casillas x 5 tipos de contenido), en el que $\mathrm{m}_{\mathrm{ij}}$ toma un valor binario (ó 1 ó 0 ) dependiendo de si el error se comete o no respectivamente. Su posición relativa dentro de la matriz nos determina a qué casilla y a qué contenido del dictado se refiere; esto es, $\mathrm{m}_{\mathrm{ij}}=1$ nos determina un error en la casilla $\mathrm{i}(\mathrm{i}=1$, $2,3,4,5)$ y contenido $\mathrm{j}$ ( $\mathrm{j}=1$ : cualidades, $2=$ cantidad, $3=$ formas, 4=tamaño, 5=orientación). Así, acorde a los contenidos descritos en el Cuadro 1, para el caso de tres años la matriz se reduce a una matriz de orden $3 \times 3$, para cuatro años es una matriz de orden $4 \times 5$ y para 5 años es una matriz cuadrada de orden 5; aunque para este trabajo analizamos exclusivamente los tres primeros contenidos, esto es, cualidades, cantidades y formas.

Para analizar las posibles variaciones en la tasa de éxito de los dictados, se ha diseñado una segunda herramienta que tiene en cuenta el índice de dificultad en la representación de los dictados según contenido, que tiene como propósito medir la dificultad de cada apartado, atendiendo al conocimiento previo de las niñas y los niños y el cambio relativo de dificultad producido en dicho contenido, esto es:

- Cualidad: la dificultad de la identificación de la cualidad c, denotada por $|\mathrm{c}|$, se considera nula en el caso de los colores primarios (rojo, amarillo, azul) y en caso de que la casilla esté compuesta por varios colores, la dificultad de c se define como la suma de las dificultades de cada elemento más el número de elementos menos 1 , esto es, $|\mathrm{c}|=\left|\mathrm{c}_{1}\right|+\ldots+\left|\mathrm{c}_{\mathrm{m}}\right|+(\mathrm{m}-1)$, donde $\mathrm{c}_{\mathrm{i}}$ son los colores que aparecen para todo $\mathrm{i}, \mathrm{y} \mathrm{m}$ el número total de colores.

- Cantidad: la dificultad de la cantidad asociada al número, denotada por $|\mathrm{n}|$, se define como $|\mathrm{n}|=\mathrm{n}-1$. En caso que la cantidad venga dada por un cuantificador (muchos, varios, pocos, ...), su dificultad será 1 . En caso de que el número esté descompuesto en suma de $\mathrm{m}$ sumandos (con $\mathrm{m}=2$ o más), la dificultad de $\mathrm{n}$ se define como $|\mathrm{n}|=\left(\mathrm{p}_{1^{-}}\right.$ $1)+\ldots+\left(p_{m}-1\right)$, donde $n=p_{1}+\ldots+p_{m}$. Así, por ejemplo, representar un elemento no tiene dificultad alguna, representar dos elementos tiene una dificultad igual a $1(|2|=2-1=1)$, pero representar el dos como descomposición de dos elementos distintos tiene dificultad $2(2=1+1 ;|2|=|1+1|=(2-1)+(2-1)=2)$. 
- Forma: la dificultad de la forma se corresponde con la siguiente gradación: círculo $<$ cuadrado $<$ triángulo $<$ segmento; por tanto, la dificultad de la forma $\mathrm{f}$, denotada por $|\mathrm{f}|$, se define como $|\mathrm{f}|=0,1,2,3$ para círculo, cuadrado, triángulo o segmento respectivamente. En caso de que la casilla esté compuesta de varias formas, la dificultad de la casilla asociada a la forma se define como la suma de las dificultades de todas las formas más el número que formas que haya menos 1, esto es, $|\mathrm{f}|=\left|\mathrm{f}_{1}\right|+\ldots+\left|\mathrm{f}_{\mathrm{m}}\right|+(\mathrm{m}-1)$, donde $\mathrm{f}_{\mathrm{i}}$ son las formas que aparecen para todo $\mathrm{i}$, y $\mathrm{m}$ el número total de formas.

\section{Resultados}

A la hora de exponer los resultados, éstos se han ordenado de acuerdo con la secuencia de objetivos del trabajo. En la primera parte, se muestra un estudio pormenorizado de los dictados realizados por algunos niños y niñas clasificados según edad y curso; dando lugar a un estudio de casos de la línea y evolución de aprendizaje de éstos en la representación simbólica, facilitando una mayor comprensión de la misma. En la segunda parte, se analiza el tipo de representación simbólica de modo colectivo, caracterizándola, por un lado, a través del grado de éxito en la realización de los dictados, haciendo un análisis cuantitativo de los errores cometidos $\mathrm{y}$, por otro, por medio de la posible justificación de estos errores en función del grado o incremento de dificultad del dictado, disgregados por edad. Finalmente, la integración e interpretación de los análisis cualitativo y cuantitativo se muestran posteriormente en las conclusiones.

\subsection{Análisis de la evolución del aprendizaje y dificultades particulares de algunos niños y niñas}

A continuación se muestra el estudio de casos acerca de la evolución del aprendizaje y dificultades particulares de algunos niños y niñas, dependiendo de su edad (por cuestiones de confidencialidad, las iniciales de los nombres son ficticias). Para ello, en algunos ejemplos se muestra el análisis del tipo de error cometido según bloque de contenido, mostrando las matrices asociadas al mismo. Además, para llevar a cabo el análisis cualitativo sobre la evolución de los dictados, en todos los casos se hace un estudio pormenorizado acorde a la motricidad, organización del espacio y reconocimiento de formas (ver Tabla 2). 


\subsubsection{Distintas evoluciones de aprendizaje en $1^{\circ}$ de Educación Infantil}

En la Figura 4 tenemos la estudiante A (tres años):
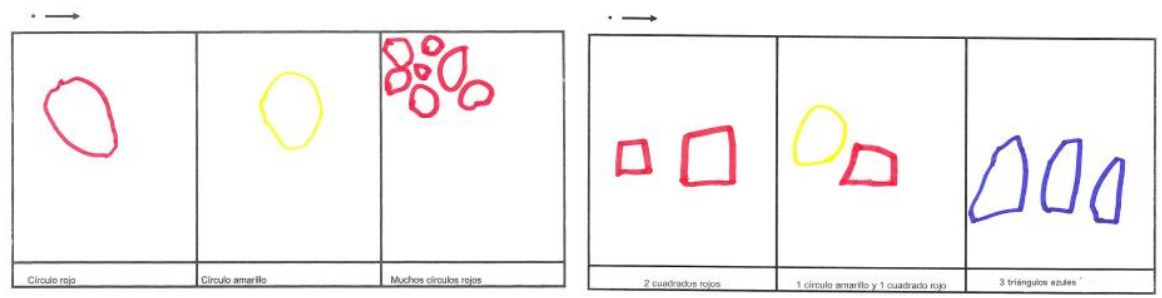

Figura 4 - Dictado del primer y último trimestre respectivamente, estudiante A Fuente: Producciones de la niña A en el CEIP Federico García Lorca de Valladolid

Si analizamos los dictados realizados por el estudiante A con respecto a los bloques de contenidos, éste no comete ningún error en la representación de ninguna casilla, salvo en la última que se equivoca en la forma de los triángulos (ver Figura 4b).

$$
m_{A 1}=\left(\begin{array}{ccc}
0 & 0 & 0 \\
0 & 0 & 0 \\
0 & 0 & 0
\end{array}\right) ; m_{A 2}\left(\begin{array}{ccc}
0 & 0 & 0 \\
0 & 0 & 0 \\
0 & 0 & 1
\end{array}\right)
$$

Figura 4b - Matrices de errores asociadas a los dictados (primer y último trimestre $m_{A 1}, m_{A 2}$ respectivamente) Fuente: Elaboración propia

Por otro lado, un análisis basado en la rúbrica definida en la Tabla 2, nos permite concluir que este niño muestra un progreso en la precisión del trazo y una mejora considerable en la distribución de las formas geométricas con respecto al espacio dado para cada casilla en el dictado del último trimestre. En cuanto a las formas de las figuras se completan los dibujos de los círculos y los cuadrados, pero los triángulos ofrecen una mayor dificultad en el trazado. Si bien se comprueba que tiene interiorizada la figura porque en la tercera casilla las representaciones se estilizan hacia arriba (ver Figura 4)

En la Figura 5 observamos el dictado de la estudiante B (tres años):
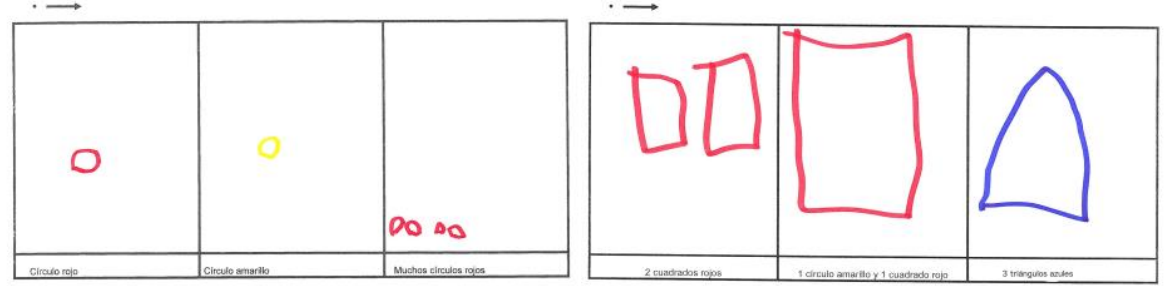

Figura 5 - Dictado del primer y último trimestre respectivamente estudiante B Fuente: Producciones de la niña B en el CEIP Federico García Lorca de Valladolid

Si analizamos los dictados realizados por la estudiante B con respecto a los bloques de contenidos, podemos ver cómo en el primer dictado ésta no comete ningún error en la representación de ninguna casilla, pero en el segundo dictado comete errores tanto por cantidad en las casillas segunda y tercera, como de forma y cualidad en la casilla segunda. 
Estos errores vienen determinados en las filas $2^{\mathrm{a}}$ y $3^{\mathrm{a}}$ de la matriz $m_{B 2}$ de la Figura $5 \mathrm{~b}$.

$$
m_{B 1}=\left(\begin{array}{ccc}
0 & 0 & 0 \\
0 & 0 & 0 \\
0 & 0 & 0
\end{array}\right) ; m_{B 2}=\left(\begin{array}{ccc}
0 & 0 & 0 \\
1 & 1 & 1 \\
0 & 1 & 0
\end{array}\right)
$$

Figura 5b - Matrices de errores asociadas a los dictados (primer y último trimestre $m_{B 1}, m_{B 2}$ respectivamente) Fuente: Elaboración propia

Aun así, haciendo uso de la rúbrica de la Tabla 2, podemos ver cómo la precisión del trazo es clara ya desde el primer trimestre, si bien utiliza una mínima parte del espacio de la página. Se percibe una mejora considerable en la distribución de las formas geométricas en el dictado final. En cuanto a las formas se evidencia que domina el círculo y el cuadrado, solamente dibuja un triángulo, en lugar de tres como se indica en el dictado, aunque esto no impide que dicha forma sea bien identificada (ver Figura 5).

En la Figura 6 tenemos el dictado de la estudiante C (tres años). En el primer trimestre el trazo es impreciso, le cuesta trabajo sujetar el rotulador, las líneas son muy finas, produciéndose ondulaciones; en cambio, al final del curso los rasgos son más claros y precisos. Ha avanzado considerablemente en este aspecto. En cuanto a la organización del espacio está bastante dominada ya desde un principio. En lo que se refiere a la forma de las figuras se produce un desarrollo notable en su representación en el último trimestre. Discrimina círculo, cuadrado y triángulo. Aunque sabemos que para los niños de tres años es muy difícil distinguir el cuadrado y el rectángulo.
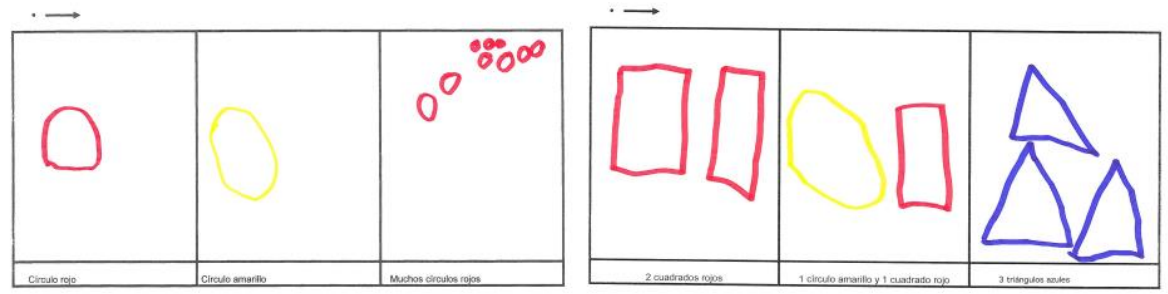

Figura 6 - Dictado del primer y último trimestre respectivamente estudiante $\mathrm{C}$ Fuente: Producciones de la niña C en el CEIP Federico García Lorca de Valladolid

\subsubsection{Distintas evoluciones de aprendizaje en $2^{\circ}$ de Educación Infantil}

El dictado del estudiante D (cuatro años) aparece en la Figura 7:
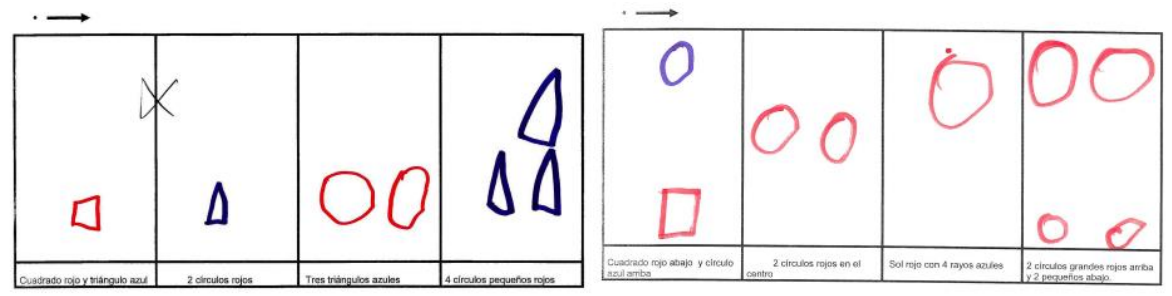

Figura 7 - Dictado del primer y último trimestre respectivamente estudiante D

Fuente: Producciones del niño D en el CEIP Federico García Lorca de Valladolid 
Si analizamos los dictados realizados por el estudiante $\mathrm{D}$, con respecto a los bloques de contenidos, podemos ver cómo en el primer dictado éste comete errores en todas las casillas solicitadas, bien sea relacionadas con el bloque que hace alusión a cualidad, cantidad, forma, (ver la matriz $m_{D I}$ de la Figura 7b); sin embargo, en el segundo dictado éste mejora sustancialmente en todos los bloques de contenidos, aunque comete algún error en la casilla tercera relacionada con cualidad, cantidad, forma (ver la matriz $m_{D 2}$ de la Figura $7 b$ ).

$$
m_{D 1}=\left(\begin{array}{ccccc}
1 & 1 & 1 & 0 & 0 \\
1 & 1 & 1 & 0 & 0 \\
1 & 1 & 1 & 0 & 0 \\
1 & 1 & 1 & 0 & 0
\end{array}\right) ; m_{D 2}=\left(\begin{array}{ccccc}
0 & 0 & 0 & 0 & 0 \\
0 & 0 & 0 & 0 & 0 \\
1 & 1 & 1 & 0 & 0 \\
0 & 0 & 0 & 0 & 0
\end{array}\right)
$$

Figura $7 \mathbf{b}$ - Matrices de errores asociadas a los dictados (primer y último trimestre $m_{D 1}, m_{D 2}$ respectivamente) Fuente: Elaboración propia

Un análisis más cualitativo del tipo de representación que realiza según la rúbrica de la Tabla 2, destaca la precisión en el trazo. Este hecho es habitual en cuatro años. Se percibe que la consigna de la primera casilla cuadrado rojo y triángulo azul la realiza usando la primera y segunda casillas. Análogamente, la consigna dos círculos rojos (perteneciente a segunda sección) pasa a la tercera casilla, y la tercera consigna la dibuja en la cuarta celdilla. El desfase producido induce a pensar que las formas están dominadas, pero necesita más tiempo para completar con éxito el dictado.

En el dictado final, lo más importante es que ya no hay desfase en las casillas, solamente está incompleta la tercera, en la que habría que colocar pequeños segmentos rayos de sol y no son dibujados; una mejor organización del espacio la consigue al final del curso, realizando correctamente el dictado (ver Figura 7).

Veamos, ahora, el estudiante E (cuatro años), en la Figura 8. Se percibe precisión en el trazo, buena organización del espacio y comprensión de formas, aunque en la última casilla del primer dictado ha intercambiado los círculos por los cuadrados. La evolución del aprendizaje es favorable en todos los matices trabajados. Se nota que en el dictado del último trimestre ha cogido el rotulador de forma distinta (las líneas son muy finas y al principio de curso gruesas, aunque, en ambos casos, el trazo el claro y suelto).
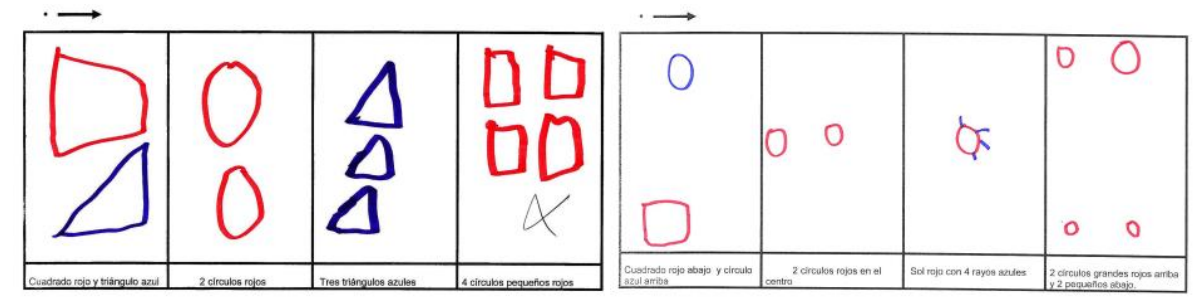

Figura 8 - Dictado del primer y último trimestre respectivamente estudiante E Fuente: Producciones del niño E en el CEIP Federico García Lorca de Valladolid 
En cuanto al estudiante F (cuatro años) observamos que, en el primer dictado destaca la imprecisión en el trazo en la segunda y cuarta celdillas. Este hecho coincide con el uso del rotulador de color rojo y sucede lo mismo en el segundo dictado. La estructura de los contenidos del dictado ya desde el primer momento está lograda y la distribución del espacio en el segundo dictado es mejor que en el primero. También se aprecia una mejora en la percepción relativa de las formas de distinto tamaño cuando éstas aparecen en la misma celdilla (Figura 9).
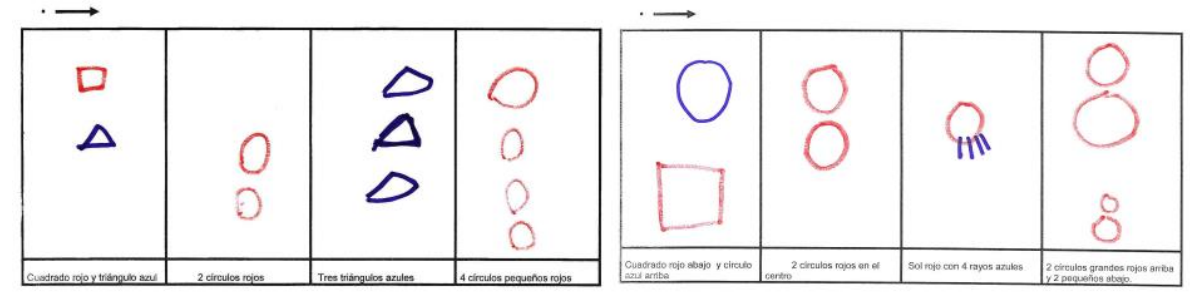

Figura 9 - Dictado del primer y último trimestre respectivamente estudiante $\mathrm{F}$

Fuente: Producciones del niño F en el CEIP Federico García Lorca de Valladolid

\subsubsection{Distintas evoluciones de aprendizaje en $3^{\circ}$ de Educación Infantil}

En lo que se refiere a la estudiante G (cinco años), desde un análisis de contenido concluimos que los dictados realizados por ella (Figura 10) muestran cómo en el primer dictado ésta no comete casi ningún error en la representación de ninguna casilla, salvo en las casillas 1, 4 y 5, en la que faltan algunas formas; sin embargo, el segundo dictado lo realiza correctamente, que se pueden consultar en las matrices de la Figura 10b.
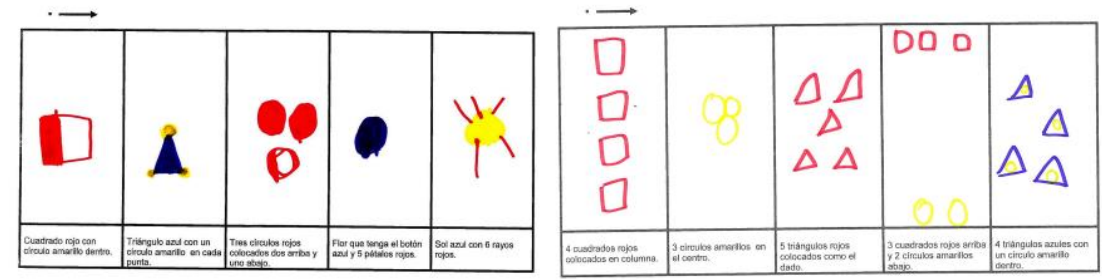

Figura 10 - Dictado del primer y último trimestre respectivamente estudiante G Fuente: Producciones de la niña G en el CEIP Federico García Lorca de Valladolid

Incluso, un análisis cualitativo de los dictados, nos permite mostrar lo más llamativo de sus representaciones, que, en este caso, es que los círculos están pintados completamente, no son circunferencias como en los demás casos. En la primera y tercera casilla no coloca el círculo dentro y los pétalos fuera respectivamente. Pero en segunda y tercera casillas es correcta la orientación. El error en la representación del sol se deba a que, normalmente, se pinta de amarillo y no de azul. Domina correctamente las formas. Al final de curso ha completado con éxito la tarea. Ahora, no pinta completamente los círculos (Ver Figura 10). 


$$
m_{G 1}=\left(\begin{array}{ccccc}
1 & 1 & 1 & 0 & 1 \\
0 & 0 & 0 & 0 & 0 \\
0 & 0 & 0 & 0 & 0 \\
1 & 1 & 1 & 0 & 1 \\
1 & 1 & 0 & 0 & 0
\end{array}\right) ; m_{G 2}=\left(\begin{array}{ccccc}
0 & 0 & 0 & 0 & 0 \\
0 & 0 & 0 & 0 & 0 \\
0 & 0 & 0 & 0 & 0 \\
0 & 0 & 0 & 0 & 0 \\
0 & 0 & 0 & 0 & 0
\end{array}\right)
$$

Figura 10b - Matrices asociadas a los dictados (primer y último trimestre respectivamente) Fuente: Elaboración propia

La Figura 11 expresa los dictados del estudiante H (cinco años). Llama la atención que la consigna triángulo azul con un círculo amarillo en cada punta lo resuelve dibujando los círculos dentro, pero sí están cerca de la punta, por lo que, a pesar de ser una representación inusual, es correcta. En el segundo dictado, sorprende que los trazos en rojo no sean precisos cuando ya lo tenía conseguido en el primer trimestre, este hecho puede deberse a problemas con la tinta del rotulador rojo.
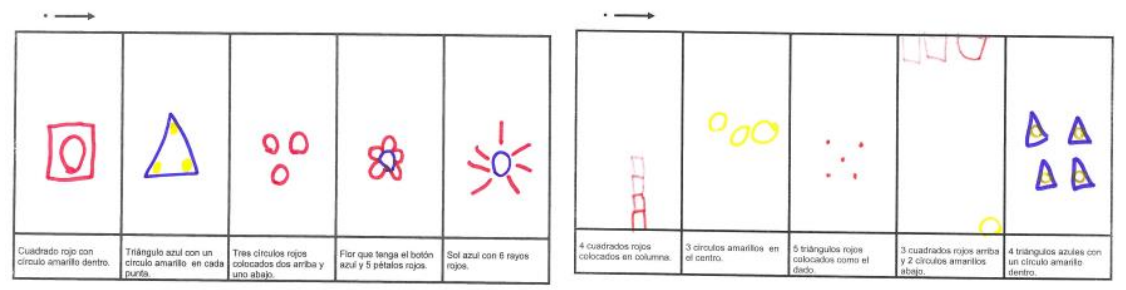

Figura 11 - Dictado del primer y último trimestre respectivamente estudiante $\mathrm{H}$

Fuente: Producciones del niño H en el CEIP Federico García Lorca de Valladolid

En cuanto al estudiante I (cinco años), en el primer dictado (Figura 12) se observa un trazo limpio y decidido y una buena organización del espacio. Hay dos fallos: en la segunda casilla no se ha colocado el círculo amarillo dentro, y en la cuarta el error es cuantitativo, coloca 6 pétalos en lugar de 5. El progreso en todos los apartados es perfecto. Se ha completado la tarea con éxito.
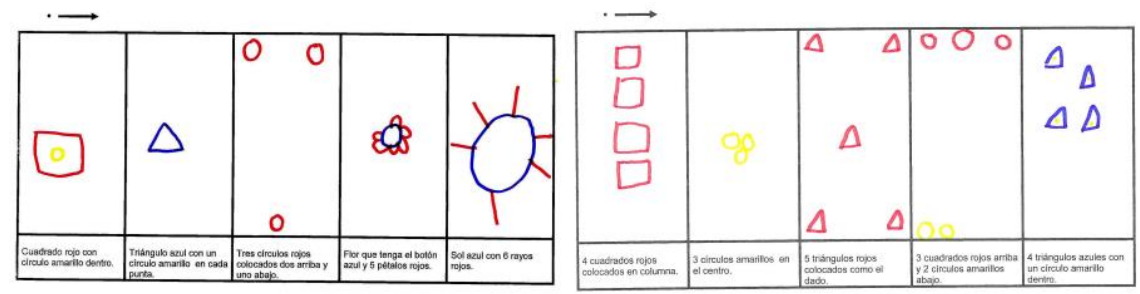

Figura 12 - Dictado del primer y último trimestre respectivamente estudiante I

Fuente: Producciones del niño I en el CEIP Federico García Lorca de Valladolid

\subsection{Análisis del tipo de representación simbólica y su evolución}

En este apartado, se analiza la evolución de los niños y las niñas en cada curso académico y nivel con respecto a los tres estándares de contenidos cualidades, cantidades y formas y su evolución con respecto a la asimilación de los contenidos involucrados en los 
dictados.

En este sentido, se muestra el grado de éxito en la realización de los dictados, por medio de la caracterización de los aspectos en qué han mejorado, qué porcentaje de errores comenten en algunos conceptos, para, posteriormente, analizar dichos errores con respecto a la evolución de la dificultad de los contenidos por sub-apartado, haciendo uso del índice de dificultad definido en el apartado anterior, disgregados por edad.

\subsubsection{Tipo de representación simbólica en tres años}

Un análisis pormenorizado de los dictados realizados en los niños y niñas de tres años, tanto en la fase inicial como final, nos da como resultado la Figura 13, en la que, acorde a cada tipo de contenido, podemos ver el porcentaje de niños y niñas que no han resuelto correctamente la tarea asociada a la casilla.

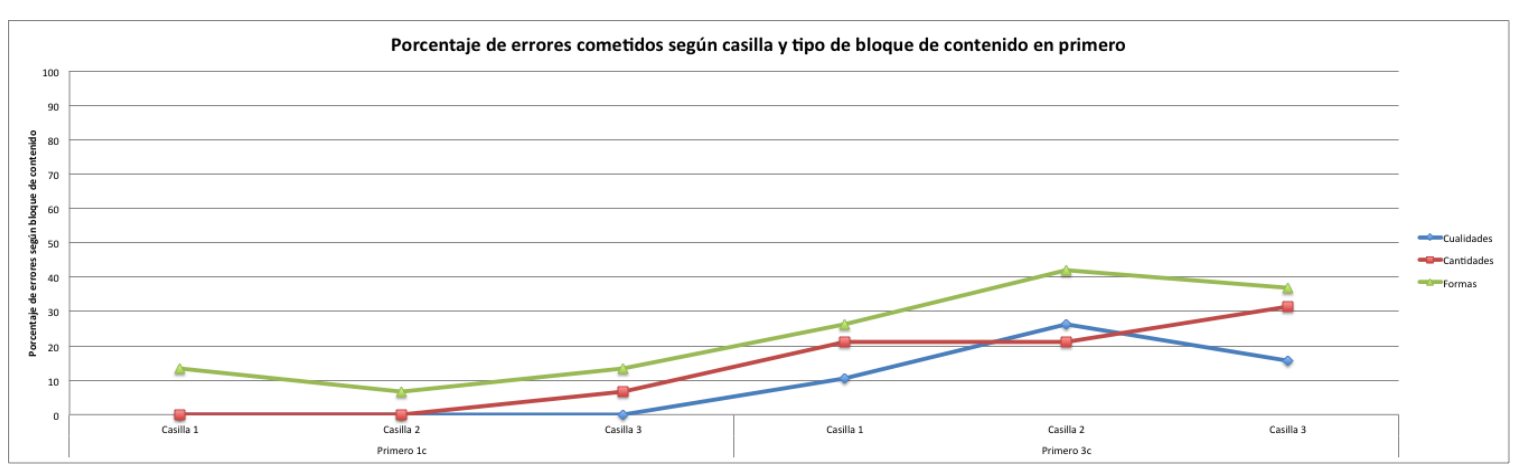

Figura 13 - Gráfica del porcentaje de errores por contenido en tres años Fuente: elaboración propia

En la Figura 13, el análisis sobre el contenido referente a las cualidades (color azul), muestra que en el primer dictado el uso de un único color no supone una dificultad en las niñas y los niños (rojo o amarillo), debido a que el porcentaje de error cometido es nulo, y por tanto, el grado de corrección del 100\%; pero en la realización del segundo dictado, al plantear el uso de dos colores distintos (en la segunda casilla) o el color azul (en la tercera casilla), este incremento en la dificultad de elección genera un conflicto cognitivo mayor, dando lugar a un porcentaje mayor de error $\mathrm{y}$, por tanto, a un grado de corrección en la realización de la tarea menor .

Para el contenido relacionado con las cantidades, podemos ver cómo para las dos primeras casillas del dictado del primer trimestre, el grado de corrección es del 100\%, que disminuye tanto en la tercera casilla de este dictado como en las dos primeras del dictado del último trimestre. Sin embargo, el porcentaje de error en la tercera casilla del último trimestre aumenta considerablemente, lo que implica que los niños y niñas tienen una mayor dificultad 
en su correcta resolución. Este hecho es debido a la introducción del cardinal número 3. En concreto, en el primer dictado los conceptos trabajados solo son el 1 y muchos; mientras que en el último dictado, se introducen los cardinales 2 (en la segunda casilla) y el 3 (en la tercera).

Para el contenido referido a las formas, en el primer dictado solamente se trabaja el concepto de círculo, mientras que en el segundo dictado se trabajan formas distintas, dando lugar a un mayor porcentaje de error, en especial, destaca la casilla dos, en la que hay que representar dos formas distintas (círculo y cuadrado) y, por tanto, los niños y las niñas muestran un mayor grado de dificultad en la resolución de esta tarea.

La dificultad asociada a cada una de las casillas, que ayuda a la interpretación de los posibles porqués, puede ser consultada en la Figura 14, en la que se puede comprobar que cuando los niños tienen que representar dos formas distintas, el índice de dificultad del dictado es considerado mayor y el porcentaje de error aumenta, acorde a la transición entre los niveles de Van Hiele.

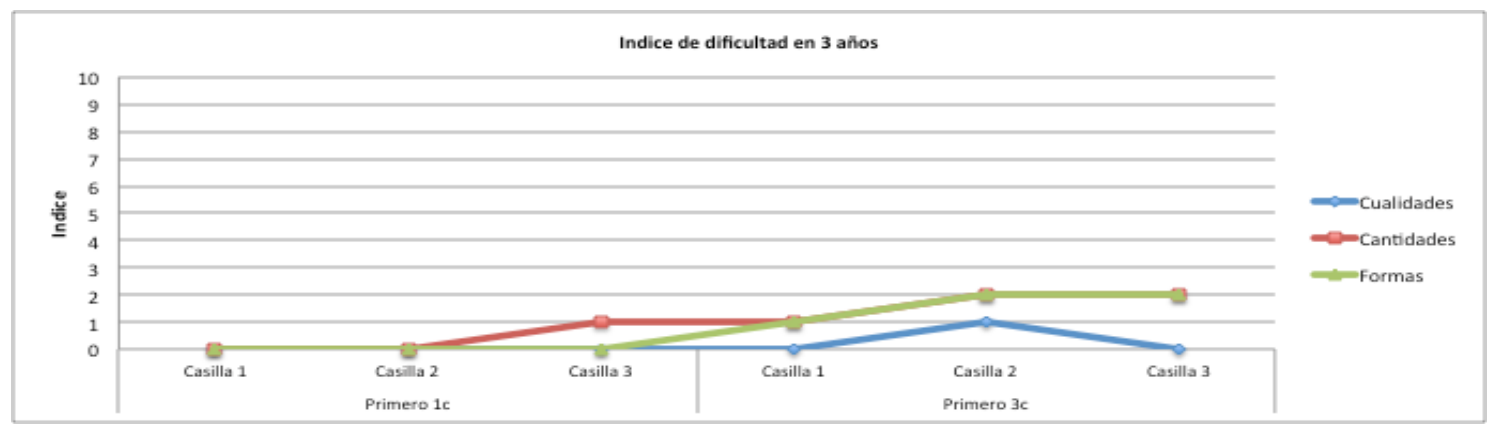

Figura 14 - Gráfica del índice de dificultad por contenido en tres años Fuente: elaboración propia

\subsubsection{Tipo de representación simbólica en 4 años}

Para el caso de los niños y niñas de cuatro años, el estudio de los dictados realizados, tanto en la fase inicial como final, nos da como resultado la Figura 15, en la que, de acuerdo con cada tipo de contenido, podemos ver el porcentaje de niños y niñas que no han resuelto correctamente la tarea asociada a la casilla. 


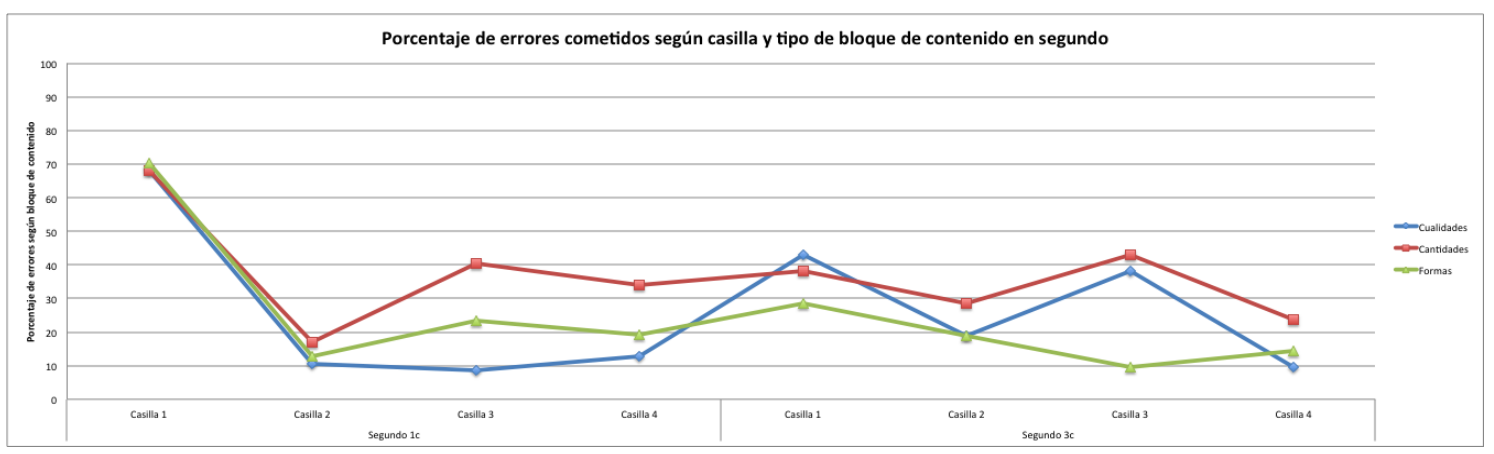

Figura 15 - Gráfica del porcentaje de errores por contenido en cuatro años Fuente: elaboración propia

En la Figura 15 se aprecia que los niños y las niñas presentan una evolución positiva en el manejo de formas o colores, pero con respecto a las cantidades, se observa que en el primer dictado los niños y las niñas muestran dificultades a la hora de representar el número 3 y el número 4, que son las cantidades más complejas a representar en esta etapa educativa (casillas 3 y 4 del primer dictado respectivamente).

El paso al segundo dictado viene marcado por un aumento en los errores cometidos, determinados por la falta de costumbre con la tarea, por tanto, la primera casilla muestra un número mayor de errores en todos los contenidos con respecto al dictado primero.

Con respecto al resto de casillas del dictado del último trimestre, destaca la casilla 3, en la que el número de errores se incrementa drásticamente; hecho debido a la dificultad de mostrar las cantidades a través de la descomposición del número 5 y de la introducción del concepto de segmento en la representación de las formas.

Por otro lado, la Figura 16 nos muestra la dificultad asociada a cada una de las casillas de los dos dictados, lo que nos permite interpretar a qué se debe el éxito o no de la realización de las tareas, analizando los posibles porqués. En este caso, destaca claramente que el aumento de la complejidad de las tareas asociadas a las cantidades (casilla 3-dictado 2), conlleva un grado mayor de error en su representación.

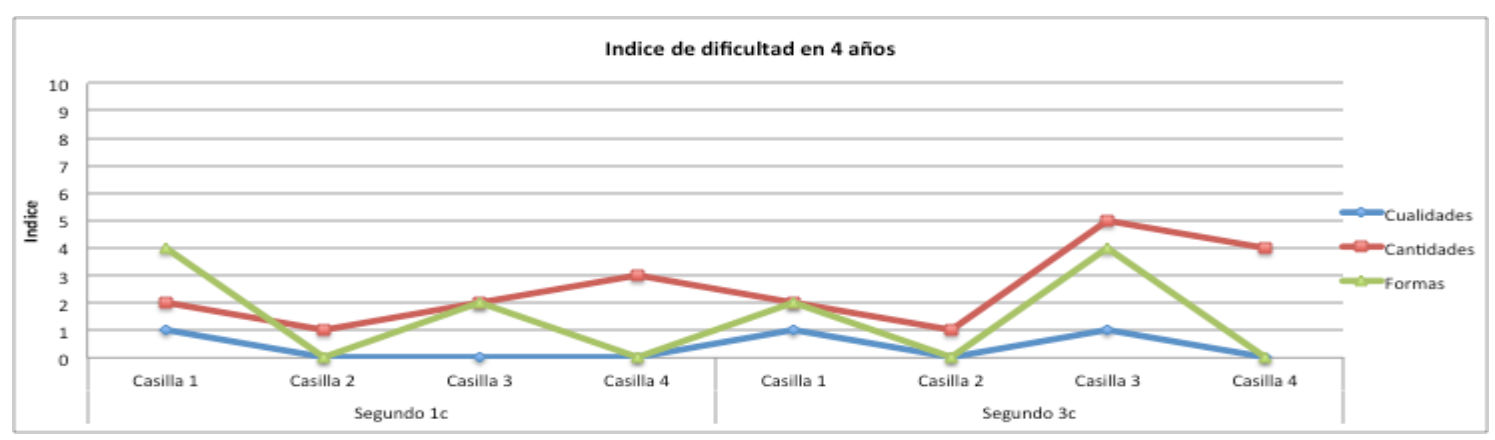

Figura 16 - Gráfica del índice de dificultad por contenido en cuatro años Fuente: elaboración propia 


\subsubsection{Tipo de representación simbólica en cinco años}

Finalmente, en cinco años, el análisis de los dictados realizados por los niños y las niñas, tanto en la fase inicial como final, nos da como resultado la Figura 17, en la que, podemos ver el porcentaje de niños y niñas que no han resuelto correctamente la tarea asociada a la casilla, clasificados por el tipo de contenido.

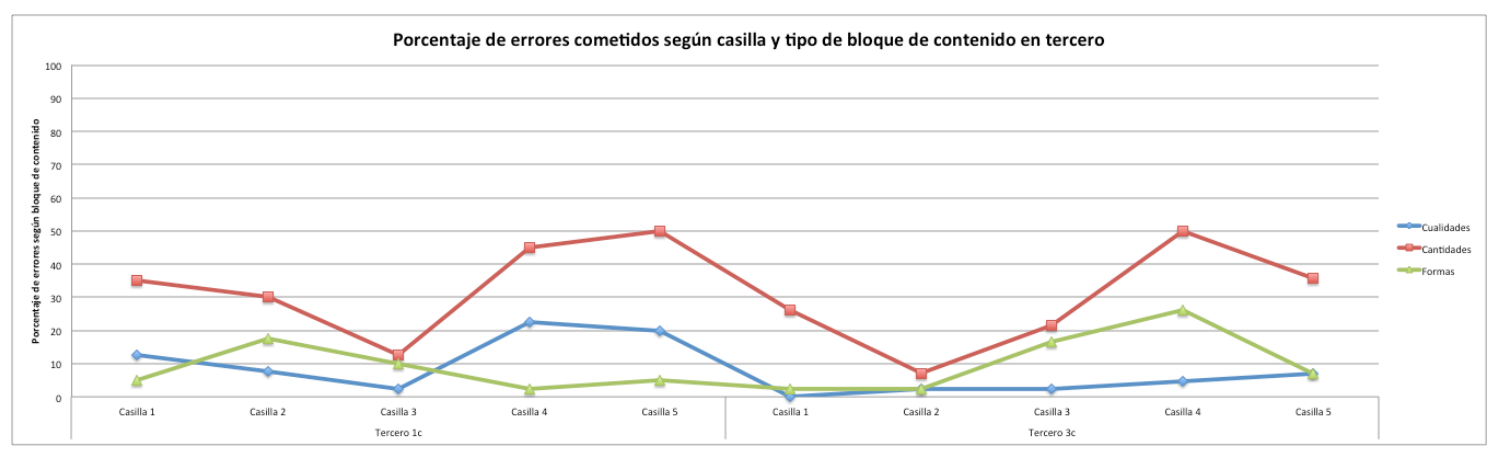

Figura 17 - Gráfica del porcentaje de errores por contenido en cinco años Fuente: elaboración propia

La Figura 17 muestra la evolución de las niñas y los niños de cinco años en la resolución de las tareas detalladas en los dos dictados; en las dos fases consideradas. Un análisis detallado del mismo nos muestra claramente los saltos de dificultad cognitivos que muestran las niñas y los niños en estas etapas, considerando los tres tipos de contenidos.

En consonancia con los niveles de Van Hiele, la introducción de las formas triángulo y segmento provocan un número más elevado de errores (casillas 2 y 5 del primer dictado y casilla 3 del segundo), este aumento en la resolución incorrecta se debe a la representación simbólica de varios objetos a la vez, lo que implica mayor abstracción y complejidad.

En el caso de las cantidades, las mayores dificultades se encuentran en la descomposición de los números 6 y 7 como $1+5$ y $1+6$ respectivamente (casillas 4 y 5 del primer dictado) y con la representación simbólica de los números 5 y 6 . En consecuencia, destacar que son las cantidades que llevan asociado un mayor grado de complejidad en dos sentidos, por ser las cantidades mayores a trabajar en el aula y por otro a que deben ser descompuestas como sumas. Esta dificultad se puede ver claramente reflejada en la Figura 18. 


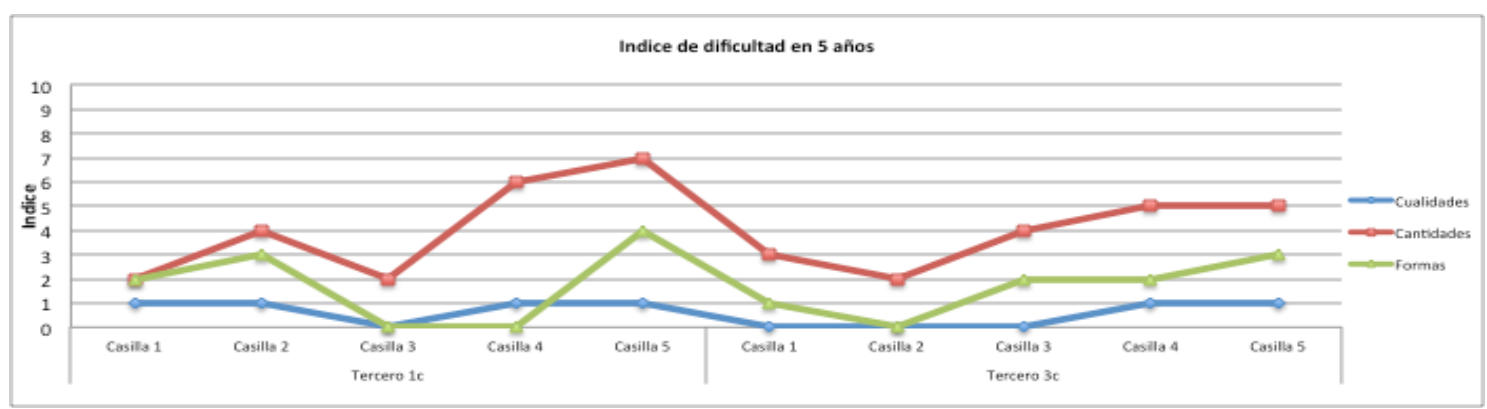

Figura 18 - Gráfica del índice de dificultad por contenido en cinco años Fuente: elaboración propia

\subsubsection{Análisis de la relación entre el de tipos de representación y el índice de dificultad de los dictados}

Una comparación minuciosa entre las gráficas relativas al índice de dificultad de los dictados (Figuras 14, 16 y 18) y las correspondientes a porcentajes de errores por edades (Figuras 13, 15 y 17), y por ende, al grado de éxito en la resolución de las tareas de representación en los dictados, muestra que los cambios drásticos en el incremento porcentual de fracaso de cada uno de los contenidos se corresponde, mayoritariamente, con el incremento en el índice de dificultad del apartado del contenido correspondiente. Igualmente, un mayor éxito en la representación simbólica del dictado lleva asociada, mayoritariamente, un incremento nulo de la dificultad del dictado (bien sea por mantener la dificultad o por disminuir parcialmente la dificultad).

Sin embargo, gracias a la comparativa de las figuras por pares en función de la edad a la que hacen referencia, podemos determinar en qué casos las niñas y los niños muestran dificultades con algún concepto, a través del análisis de los errores en tareas consecutivas en las que se repite el concepto, o por realización de una tarea equivalente sin incremento de dificultad; así, por ejemplo:

- En tres años, vemos que las niñas y los niños tienen una mayor dificultad en la representación de triángulos frente a otras formas; también se muestran los posibles problemas que tienen para representar simbólicamente el número 3, frente a los cardinales 1 y 2 y la descomposición del 2 como $1+1$.

- En cuatro años, muestran ciertas dificultades en la descomposición del número 5.

- $\quad$ En cinco años, destaca el porcentaje de estudiantes que muestran dificultades con la representación del triángulo, forma a priori trabajada en los cursos anteriores. También muestran dificultades con la representación de cardinales más grandes como sumas de otros menores. 


\section{Conclusiones}

Tal como hemos mostrado a lo largo de todo el texto, autores cmo Piaget e Inhelder (1966) o Bruner (1966) ya destacaron la necesidad de trabajar en el aula de infantil tareas de representación que crearan un puente entre el lenguaje y la representación de imágenes mentales asociadas. En este sentido, el presente trabajo ha tenido un primer objetivo centrado en el análisis cualitativo de los dictados, que nos ha permitido concluir algunas de las características de aprendizaje en el caso de los niños y las niñas, dependiendo de su edad.

Así, para tres años, se ve una evolución favorable en la motricidad del alumnado, al igual que una mejor ubicación y reparto espacial y la interiorización de algunos objetos geométricos más complejos, como son los triángulos de acuerdo con los Niveles de Van Hiele. Igualmente, se observa una interiorización clara de cardinales pequeños o cuantificacores prenuméricos.

Para el caso de cuatro años, ya desde el comienzo se observa que, en general, hay un dominio correcto del trazo, como señala Berruezo (2000), pero no se tiene un uso correcto del tiempo para el desarrollo de los sub-apartados, dando lugar a desfases en la representación en algunos casos.

En la edad de cinco años, en todos los casos se observa que, además de tener estos aspectos bastante trabajados (trazo, organización espacial y formas), los niños y las niñas avanzan a una representación simbólica más explícita y correcta, compatible con el establecimiento de relaciones con las características de los objetos matemáticos involucrados (según las interpretaciones de BOULE, 2005; HOLLOWAY, 1982).

Con respecto al análisis cuantitativo, destacar la utilidad de los dictados en las distintas etapas de aprendizaje de educación infantil para baremar, por un lado, el porcentaje de niños y niñas que no tienen interiorizada la representación de algún concepto matemático o cualidad del mismo, y, por otro, para poder graduar la complejidad que se puede definir en el dictado dependiendo de la fase de desarrollo cognitivo de nuestros estudiantes.

Así, para el caso de tres años se ve un gran salto en la dificultad cognitiva asociada al tratamiento del cardinal 1 o al del 2 y el 3. Para el caso de cuatro años, la descomposición de cardinales pequeños como suma de otros $(2=1+1)$ significa una dificultad añadida; mientras que para la edad de cinco años, la dificultad proviene de la descomposición de cardinales más grandes como sumas de 2 números dados.

Estos resultados refuerzan las ideas asociadas a las trayectorias de aprendizaje de Clements y Sarama (2015), en las que, para el caso de las cantidades, queda latente que el 
conocimiento numérico a temprana edad incluye diferentes niveles de desarrollo significativo. En lo que se refiere a números pequeños no suelen tener dificultades con uno o dos objetos y pueden discriminar de uno a cuatro. Aumenta la dificultad cuando los grupos de objetos son compuestos.

Por otro lado, la complejidad asociada a la representación de formas geométricas resulta acorde a los niveles de Van Hiele (1999) y a resultados previos asociados a la representación e identificación de formas planas como cuadrados y triángulos (HALAT; YESIL-DAGLI, 2016; YESIL-DAGLI; HALAT, 2016) respectivamente. En este sentido, en todas las edades los niños y niñas encuentran dificultades en la representación de triángulos, dificultad que disminuye con el paso del curso y la repetición de la tarea asociada.

Igualmente, en este trabajo logramos demostrar que el indice de dificultad del dictado y el tipo de representación que son capaces de hacer los niños y niñas están relacionados de modo inverso, esto es, a mayor dificultad en el dictado, un mayor porcentaje de error en su representación y, por ende, un menor grado de corrección en su resolución. Este hecho nos permite concluir que el dictado es una herramienta eficaz para ver en qué medida, una vez introducido el incremento de dificultad concerniente a un estándar de contenido, éste es trabajado de modo significativo en clase, a través de su correcta representación.

Vale resaltar, para concluir, que la repetición del dictado con cierta frecuencia favorece el análisis de la evolución de la comprensión que los niños y las niñas tienen sobre un concepto matemático, y, por tanto, son capaces de resolver tareas asociadas a éste con mayor facilidad, pudiendo valorar de un modo más sistemático si el aprendizaje de los niños y de las niñas es o no significativo.

Para finalizar, queremos destacar que a pesar de las limitaciones del estudio (tamaño de la muestra, selección de centros etc.), este trabajo nos induce a concluir, por un lado, que debemos realizar una incorporación sistemática de los dictados matemáticos en educación infantil como una herramienta didáctica que relaciona la compresión oral con la representación simbólica (de acuerdo con BERCIANO; NOVO; ALSINA, 2017) con el objetivo de trabajar la representación mental (BERDONNEAU, 2008; CHAMORRO, 2005); $\mathrm{y}$, por otro, como herramienta de evolución del aprendizaje, pudiendo contextualizar el tipo de representación simbólica que los niños y niñas de nuestra clase son capaces de realizar en un momento y contexto concretos.

Finalmente, debemos destacar que el dictado, por sí mismo, no tendrá valor si éste no está acompañado de un análisis contextualizado de la dificultad del mismo a través de: 1) el propio diagrama de tendencias de errores, que muestra qué tipo de problemas tiene el 
alumnado considerado en el modo del análisis, permitiendo el diseño de futuras acciones de aprendizaje más personalizadas y eficientes; 2) el análisis conjunto de la tasa de error y el índice de dificultad del dictado, que permite ver la adecuación de la elección realizada en esta tarea y confronta las trayectorias hipotéticas de aprendizaje con la realidad del aula (SARAMA ; CLEMENTS, 2009).

\section{Referencias}

ALSINA, C. et al. Enseñar Matemáticas. Barcelona: Graó, 2007.

ARDANAK, T. La psicomotricidad y la educación infantil. Innovación y Experiencias Educativas, Granada, n.16, p. 1 - 9, 2009.

ARRIAGA, C.; MADARIAGA, J. Condicionantes contextuales de la motivación para el aprendizaje de la música. Revista de Psicodidáctica, Bilbao, n. 17, p. 65 - 73, 2004.

BAROODY. A. J. El pensamiento Matemático de los Niños. Madrid: Aprendizaje Visor, 1994.

BERCIANO, A.; NOVO, M.L.; ALSINA, A. Dictados matemáticos: una herramienta para trabajar la competencia oral y escrita en el aula de matemáticas de Educación Infantil. UNIÓN. Revista

Iberoamericana de Educación Matemática, São Paulo, n. 49, p. 200-216, 2017.

BERDONNEAU, C. Matemáticas Activas (2 - 6 años). Barcelona: Graó, 2008.

BERRUEZO, P. P. La psicomotricidad en España: de un pasado de incomprensión a un futuro de esperanza. Revista Interuniversitaria de Formación del Profesorado, Zaragoza, n. 37, p. 21 - 23, 2000 .

BOULE, F. Reflexiones sobre la Geometría y su enseñanza. Colección Formarse para enseñar. México: Correo del Maestro y Ediciones La Vasija, 2005.

BRUNER, J. S. Towards a Theory of Instruction. New York: Norton, 1966.

BRYMAN, A. Integrating quantitative and qualitative research: how is it done? Qualitative research, London, v. 6, n. 1, p. 97 - 113, 2006.

CAMERON, R. Mixed methods in VET research: Usage and quality. International Journal of Training Research, Mawson Lakes, South Australia, n. 8, v. 1, p. 25 - 39, 2010.

CANALS, M. A. Vivir las Matemáticas. Barcelona: Octaedro, 2001.

CHAMORRO, C. Didáctica de las Matemáticas para Educación Infantil. Madrid: Pearson Educación, 2008.

CLEMENTS, D.; SARAMA, J. El Aprendizaje y la Enseñanza de las Matemáticas a Temprana Edad. Gran Bretaña: Learning Tools LLC, 2015.

DEVLIN, K. El lenguaje de las Matemáticas. Barcelona: Ediciones Robinbook, 2002.

DÍAZ LÓPEZ, S. M. Los Métodos Mixtos de Investigación: Presupuestos Generales y Aportes a la Evaluación Educativa. Revista Portuguesa de Pedagogia, Coimbra, p. 7 - 23, 2014. 
EDO, M. Ahí empieza todo. Las matemáticas de cero a tres años. Números, La Laguna, n. 80, p. 7184, 2012.

FISCHBEIN, E. Intuition in Science and Mathematics: An educational approach. Dordrecht: Kluwer, 1987.

FRACA DE BARRERA, L. El procesamiento psicolingüístico del dictado y sus implicaciones para la enseñanza de la lengua escrita. Investigación y Postgrado, Caracas, v. 22, n. 1, p. 93 - 108, 2007.

GREENE, J.C.; CARACELLI, V.J.; GRAHAM, W. F. Toward a conceptual framework for mixedmethod evaluation designs. Educational evaluation and policy analysis, Washington, v. 11, n. 3, p. $255-274,1989$.

HALAT, E.; YESIL-DAGLI, U. Preschool Students' Understanding of a Geometric Shape, the Square. BOLEMA, Boletim de Educação Matemática, Rio Claro, v. 30, n. 55, p. 830-848, 2016.

HOLlOWAY, G. Concepción del Espacio en el Niño Según Piaget. Madrid: Paidós, 1982.

LLACH, S.; ALSINA, À. ¿Cómo enseñar la notación lingüística y matemática? Un triple enfoque: epistémico, interdisciplinar y sociocultural. Revista Española de Pedagogía, Logroño, n. 252, p. 321336, 2012.

MARTÍ, E.; POZO, J. I. Más allá de las representaciones mentales: la adquisición de los sistemas externos de representación. Infancia y aprendizaje, Madrid, v. 23, n. 2, p.11 - 30, 2000.

MOSCOSO, J.N. Los métodos mixtos en la investigación en educación: hacia un uso reflexivo.

Cadernos de Pesquisa, São Paulo, v. 47, n. 164, p. 632 - 649, 2017.

MOYA, J. A.; GARCÍA, E. J. El dictado y la comprensión auditiva: un intento de complementariedad. En: Asociación para la Enseñanza del Español como Lengua Extranjera (Ed.). El Español como lengua extranjera: aspectos generales: edición facsimilar de las actas de las primeras Jornadas Pedagógicas y del Primer Congreso Nacional de ASELE (Asociación para la Enseñanza del Español como Lengua Extranjera). Málaga: ASELE, 1998. p. 204 - 210.

NCTM- NATIONAL COUNCIL OF TEACHERS OF MATHEMATICS. Principios y estándares para la educación matemática. Sevilla: SAEM Thales, 2003.

NOVO, M. L. Análisis de la educación matemática infantil desde la perspectiva del conexionismo. 2015.474 p. Tesis (doctorado en Didáctica de la Matemática) - Universidad de Valladolid, Valladolid, 2015.

Disponible en: < https://www.educacion.es/teseo/mostrarRef.do?ref=1190907>. Acceso en: 10 de noviembre de 2017.

NOVO, M. L.; BERCIANO, A.; FERNÁNDEZ, E. Dictados matemáticos en el aula de infantil. Uno. Revista de Didáctica de las matemáticas, Barcelona, v. 78, p. 57-63, 2017.

OCDE -ORGANIZACIÓN PARA LA COOPERACIÓN Y EL DESARROLLO ECONÓMICOS. ¿La asistencia a educación infantil se traduce en mejores resultados en el aprendizaje escolar? Pisa in Focus, 2011/1. Disponible en:

$<\mathrm{http}$ ///www.oecd.org/pisa/pisaproducts/pisainfocus/PiF1_esp_revised.pdf $>$. Acceso en: 15 de diciembre de 2017.

PÉREZ-ECHEVARRÍA, M.; MARTÍ, E.; POZO, J. Los sistemas externos de representación como herramientas de la mente. Cultura y Educación, Madrid, v. 22, n. 2, p. 133 - 147, 2010. 
PIAGET, J.; INHELDER, B. Psicología del Niño. 17. ed. Madrid: Morata, 1969/2007.

PLANAS, N.; ALSINA, À. Educación Matemática y Buenas Prácticas. Infantil, primaria, secundaria y educación superior. Barcelona: Graó, 2009.

SARAMA, J.; CLEMENTS, D. H. Early Childhood Mathematics Education Research. Learning Trajectories for Young Children. Nueva York: Routledge, 2009.

TALL, D. Cognitive and social development of proof through embodiment, symbolism \& formalism. En: FIN, F. L. et al. (Ed.). Proof and Proving in Mathematics Education: the ICMI Study 19 conference. Taipei: v. 2, 2009. p. 220-225.

TALL, D. How humans learn to think mathematically: Exploring the three worlds of mathematics. New York: Cambridge University Press, 2013.

VAN HIELE, P. M. (1959/1985). The child' s thought and geometry. En: FUYS, D.; GEDDES, D.; TISCHLER, R. (Ed.). English translation of selected writings of Dina van Hiele-Geldof and Pierre M. van Hiele. Brooklyn, NY: Brooklyn College, School of Education. (ERIC Document Reproduction Service $N^{\circ} .189$ 697). p. 243-252.

VAN HIELE, P. M. Structure and Insigh: A theory of mathematics education. Orlando: Academic Press, 1986.

VAN HIELE, P. M. Begin with play. Teaching Children Mathematics, Reston, VA 20191, v. 6, p. $310-316,1999$.

VIERA, A. El desarrollo del lenguaje y la actividad Matemática, dos elementos básicos en la práctica educativa en la etapa infantil. Participación Educativa, Madrid, n. 12, p. 77 - 86, 2009.

YESIL-DAGLI, U.; HALAT, E. Young Children's Conceptual Understanding of Triangle. Eurasia Journal of Mathematics, Science \& Technology Education, London, v. 12, n. 2, p. 189 - 202, 2016.

Submetido em 20 de Abril de 2018. Aprovado em 19 de Novembro de 2018. 